\title{
Comprehensive outpatient rehabilitation increases the ability of people over 60 to live independently
}

\author{
Magdalena Czarkowska ${ }^{1, \mathrm{~A}-\mathrm{F} \oplus}$, Tomasz Saran ${ }^{2, \mathrm{~A}, \mathrm{E}-\mathrm{F} \oplus}{ }^{\text {, Anna Mazur }}{ }^{2, \mathrm{C}, \mathrm{E}-\mathrm{F} \oplus}{ }^{\oplus}$, Lech Panasiuk ${ }^{1, \mathrm{E}-\mathrm{F}} \oplus$ \\ 1 Institute of Rural Health, Lublin, Poland \\ 2 Department of General and Neuro Rehabilitation, Institute of Rural Health, Lublin, Poland \\ A - Research concept and design, B - Collection and/or assembly of data, C - Data analysis and interpretation, \\ $D$ - Writing the article, $E$ - Critical revision of the article, $F$ - Final approval of article
}

Czarkowska M, Saran T, Mazur A, Panasiuk L. Comprehensive outpatient rehabilitation increases the ability of people over 60 to live independently. Ann Agric Environ Med. 2018; 25(4): 720-724. doi: 10.26444/aaem/99642

\begin{abstract}
I Abstract
Introduction. The answer to current social and health needs of people aged over 60 are the multidirectional and carefully planned, comprehensive activation and rehabilitation activities carried out as part of Daycare Centres (DCC). The aim of creating and the functioning of DCCs deployed all over Poland is to improve the health and psychophysical fitness of this group of people. Health factors and psychophysical fitness determine the ability to live independently, both today, and later in life.

Objective. The objective of the study was to assess the impact of comprehensive ambulatory rehabilitation, including tailored endurance training preceded by an ergospirometry test, on indicators demonstrating the ability to live independently and the risk ratio of future health problems in the elderly.

Materials and method. 60 people participating in a rehabilitation cycle implemented as part of the services provided to patients aged over 60 in the DCC of the Witold Chodźko Institute of Rural Medicine (IMW) in Lublin comprised the sample. The tests were carried out in the test-retest model on the first and last day of the kinesiotherapy cycle. Patients were tested using standardized Barthel, I-ADL and VES-13 questionnaires. The rehabilitation programme applied included systemic kinesiotherapy (endurance training) with a load determined according to individual exercise capacity, determined on the basis of a ergospirometry test, and varied rehabilitation activities resulting from the condition of the locomotor system, as provided for under the project.

Results. After completing the rehabilitation cycle, patients obtained higher results in comparison to the tests carried out before the beginning of the cycle in the Barthel index used to measure functional efficiency $(Z=5.41 ; p=0.001)$, as well as lower in the I-ADL scale used to test the degree of dependence on the help of others when performing complex activities of everyday life $(Z=2.63 ; p=0.009)$ and in VES-13 scale used to assess the risk of geriatric health problems $(Z=5.47 ; p=0.001)$. Conclusions. As the result of the use of comprehensive rehabilitation, including obligatory endurance training, desired changes were achieved in terms of fitness and independence in performing advanced daily activities and reducing the risk of geriatric health problems.
\end{abstract}

\section{Key words}

ES-13, I-ADL, Barthel index, independent existence, seniors, rehabilitation, endurance training

\section{INTRODUCTION}

The aging process of Polish society observed over the last years is a challenge for modern medicine as well as for healthcare systems. According to forecasts, by 2050, 20.0\% of the population of seniors will be over the age of 80 . The main reasons for this state include the progress of medical technologies and the associated improvement in the quality of health services provided, as well as an increase in public awareness in the field of preventive care which, among other things, includes systematic physical activity adjusted to physical health $[1,2,3]$. Numerous modern scientific reports indicate that the aforementioned type of behaviour favours the improvement of the general health condition, including also increased motor and intellectual efficiency, which in turn leads to an increase in the quality of life of the elderly [4].

Address for correspondence: Anna Mazur Institute of Rural Health in Lublin, Poland Jaczewskiego 2, 20-090, Lublin, Poland

e-mail: annamazur10@o2.pl

Received: 11.07.2018; accepted: 07.11.2018; first published: 30.11 .2018
The answer to the current social and health needs of people over 60 is the multidirectional and well-planned comprehensive activation and rehabilitation activities carried out as part of the Daycare Centre (DCC) at the W. Chodźko Institute of Rural Medicine (IMW) in Lublin. According to the assumptions of the project, the aim is to improve the health conditions and the related psychophysical fitness of seniors, and therefore factors determining their ability to live independently in old age [5]. The DCC project at the Institute of Rural Medicine is implemented according to the guidelines contained in the 'DCC in Lublin' under the POWER number.05.02.00-00-0109/15.

The key indicator of independence from other people's help is functional efficiency, both in the scope of performing basic life activities, including, among others, moving around, dressing and undressing and maintaining personal hygiene, as well as more complex activities, including use of the telephone, performing various household tasks, or managing financial affairs $[6,7,8]$.

Over the years, due to ongoing neurodegenerative 
changes, this efficiency deteriorates and becomes visible as the weakening of muscle strength, decrease in visualmotor coordination, as well as lowered efficiency of the whole organism. This is often associated with a decrease in the motivation to undertake physical activity, which in turn translates into a further decline in the independence of seniors and increases the need for care [9]. It has also been shown that apart from the age, other factors determining the functional efficiency of seniors are their level of education, financial situation, body mass index (BMI) and the presence of chronic diseases [10].

The indicator linked to the reduced functional capacity of people aged over 60 is the increase in susceptibility to the occurrence of geriatric health problems (VES-13) [11, 12, 13]. According to the current data of GUS (Central Statistical Office of Poland), seniors constitute the dominant group of patients in most hospital wards [14]. In addition, elderly patients are more frequently admitted to hospitals in a severe clinical condition, require longer periods of hospitalization, more and more advanced diagnostic tests, and more often require re-treatment in a hospital setting [9]. The immediate causes of this condition are the comorbidity and complexity of diseases, their atypical course, emotional and/or cognitive disorders, risks associated with the pharmacotherapy used, the lack of consistency in compliance with a doctor's orders, and a significant degree of disability of this group of patients [15].

In order to improve the psycho-somatic health condition and the related ability of independent existence of seniors, various types of preventive measures are directed to this group of patients, including both primary and secondary prophylaxis. The assessment of the effectiveness of the rehabilitation programme applied by the Yang team to the elderly showed that as a result of a 12-week kinesiotherapy cycle, the functional improvement of the seniors in terms of balance was achieved. It was also seen in the subjects that the intervention contributed to a significant reduction in depressive symptoms and the level of stress experienced. The above-mentioned studies allow the conclusion that the applied programme for the improvement of people over 60 is conducive to achieving the desired effects, both physical and affective which, at the same time, emphasizes the need to develop, implement and evaluate such projects in Polish society [16].

\section{OBJECTIVES}

The objective of the study was to assess the impact of comprehensive ambulatory rehabilitation, including tailored endurance training preceded by an ergospirometry test, on indicators showing the ability to live independently (Barthel index, $I-A D L)$ and the risk of geriatric health problems VES-13.

\section{MATERIALS AND METHOD}

60 seniors aged $60-93(M=74.06, S D=7.75)$ participated in the research as well as in the DDOM project carried out in IMW in Lublin. Three-quarters of the surveyed group were women (75.0\%, $N=45)$. All participants came from Lublin $(100.0 \%$, $\mathrm{N}=60$ ). The subjects with post-secondary education prevailed
(45.0\%, $\mathrm{N}=27)$, whereas $21.7 \%(\mathrm{~N}=13)$ of the respondents graduated from high schools, $18.3 \%(\mathrm{~N}=11)$ had a university degree and $1.5 \%(\mathrm{~N}=9)$ subject completed primary school.

The criterion for participation in the project was a minimum of 3-day hospitalization in the last 12 months before admission to DDOM.

The majority of patients were admitted with the diagnosis of ischemic heart disease and its consequences $(22.9 \%$, $\mathrm{N}=16)$, the diagnosis of respiratory system diseases $(14.3 \%$, $\mathrm{N}=10$ ), osteoarticular system, muscular and connective tissue diseases $(14.3 \%, \mathrm{~N}=10)$, nervous system $(12.9 \%, \mathrm{~N}=9)$, symptoms of diseases and abnormal laboratory test results $(10.0 \%, \mathrm{~N}=7)$, endocrine disorders, nutritional problems and metabolic transformation $(5.7 \%, \mathrm{~N}=4)$, mental disorders and behaviour disorders $(5.7 \%, \mathrm{~N}=4)$, cancers and blood diseases $(4.3 \%, \mathrm{~N}=3)$, urogenital tract disorders $(4.3 \%, \mathrm{~N}=3)$, as well as injuries and poisonings $(2.9 \%, \mathrm{~N}=2)$. However, the lowest percentage of respondents were patients with congenital malformations, distortions and aberrations $(1.4 \%, \mathrm{~N}=1)$ and those who contacted the health service in order to obtain consultations and advice other than classified elsewhere $(1.4 \%, \mathrm{~N}=1)$.

The research group was dominated by patients taking medications for hypertension and its complications (45.0\%, $\mathrm{N}=27$ ), followed by those who took oral antidiabetic drugs and insulin $(8.3 \%, \mathrm{~N}=5)$, drugs administered in diseases of the central and peripheral nervous system $(6.7 \%, \mathrm{~N}=4)$, drugs affecting the muscles and structures of the motor system $(6.7 \%, \mathrm{~N}=4)$, drugs against gastrointestinal diseases (6.7\%), $\mathrm{N}=4)$, drugs administered in dementia syndrome and other psychiatric disorders $(6.7 \%, \mathrm{~N}=4)$, non-steroidal anti-inflammatory drugs and opioid analgesics $(5.0 \%, \mathrm{~N}=3)$ and drugs administered in asthma and chronic obstructive pulmonary disease $(5.3 \%, \mathrm{~N}=3)$.

The research was a longitudinal study.The duration of patient's stay in DCC was determined individually by the therapeutic team and ranged from 30-120 working days. The physiotherapy actions included:

- adapted, intensive systemic kinesiotherapy (endurance training) with loads determined according to individual exercise capacity, as determined on the basis of a ergospirometry test, training plan: 8 minutes of exercycle exercises for the first 5 days with the achievement of submaximal heart rate, and 15 minutes of such exercises for the rest of the training cycle;

- varied rehabilitation activities recommended according to the needs resulting from the condition of the locomotor system, e.g. local kinesiotherapy according to the needs of the locomotor system with the use of: balls, exercise sticks, ladders, mattresses, upper limb rotor, rotor for lower limb exercises, rehabilitation table, Universal Motor Improvement Cabin, local cryotherapy, manual massage, electrotherapy, light therapy, electromagnetic field treatment.

The Barthel index [17] and the $\boldsymbol{I}-\boldsymbol{A D L}$ were used for assessing instrumental daily life activities [18], and the VES13 scale [11] to assess the risk of occurrence of geriatric health problems.

The Barthel index is a tool for assessing the patient's level of fitness and independence and the associated level of demand for care. The questionnaire includes 10 everyday activities: eating meals, moving from bed to chair and back, 
sitting down, maintaining personal hygiene, use of the toilet, maintaining personal hygiene, moving on flat surfaces, climbing and going down stairs, dressing and undressing, and controlling physiological activities. The potential range of the assessment ranges from $0-100$ points, with a score from $0-20$ points indicating total reliance on others, $21-80$ points indicating that the patient requires the care of other people to some extent, and the score from 81-100 points suggesting that the subject can function alone using only a small amount of help. A score of $0-40$ points indicates the need to qualify the patient for long-term care, because he or she requires constant care [17].

The $I-A D L$ scale is used to evaluate complex activities of everyday life. It contains 8 questions that concern dealing with use of telephone, getting to places located outside walking distance, shopping for groceries, preparing meals, performing housework, DIY or washing, preparing and taking medicines, and managing financial matters. The potential range of the test results for subjects is $8-24$ points, with a score of $8-9$ points indicating that the subject is almost independent of help from others, $10-17$ points means moderate dependence, and a score of 18-24 points informs about a serious dependence of the patient on the help of others in the field of performing complex activities of everyday life [18].

The VES-13 scale is a recognized diagnostic tool for determining the level of risk of occurrence of geriatric health problems. The questionnaire consists of 13 tasks that include questions about the age category of the subject, selfassessment of health and functional fitness, which consists of shopping, managing financial matters, performing light housework, bathing, writing or holding small items, and performing heavy housework as well as physical fitness involving lifting and moving objects weighing about $4.5 \mathrm{~kg}$, reaching or stretching arms above shoulders and walking over a distance of more than $1.5 \mathrm{~km}$. The range of results for the age question ranges from $0-3$ points, for the selfassessment of health falls within the range of $0-1$ point, and each difficulty in the independent performance of the patient scores 1 point. On the whole scale, the examined person can obtain a score from $0-15$ points, the higher the score, the higher the risk of occurrence of geriatric problems in the examined person [11].

Participation of patients in the study was voluntary and anonymous, and conducted in 2016-2018 in accordance with the Declaration of Helsinki of 2013. The participants were informed about the purpose and course of the study, and also expressed their written consent to participate. The subjects completed the tests twice - on the first and last day of the rehabilitation cycle, which they undertook during their stay at the DCC.

Permission was obtained from the Bioethics Committee of the W. Chodźko Institute of Rural Medicine (IMW) in Lublin (No. 6/2018) to use the DDOM projct's database. Statistical analyzes were performed using the IBM SPSS 24 software suite. The characteristics of the studied population were prepared on the basis of the mean value, standard deviation, minimum and maximum of quantitative variables, and distribution of the percentage frequency of occurrence of qualitative variables. The distribution patterns of the tested parameters were verified using the Shapiro-Wilk test. To verify the intra-group differences, the non-parametric Wilcoxon test was used, where the effect size was measured with the use of the Cohen two-series rank correlation coefficient for matching pairs $(r)$. The study assumed the limit level for false positive error of 0.05 .

\section{RESULTS}

Results of the performed intergroup comparisons in the range of results obtained in Barthel index are included in Table 1 and Figure 1.

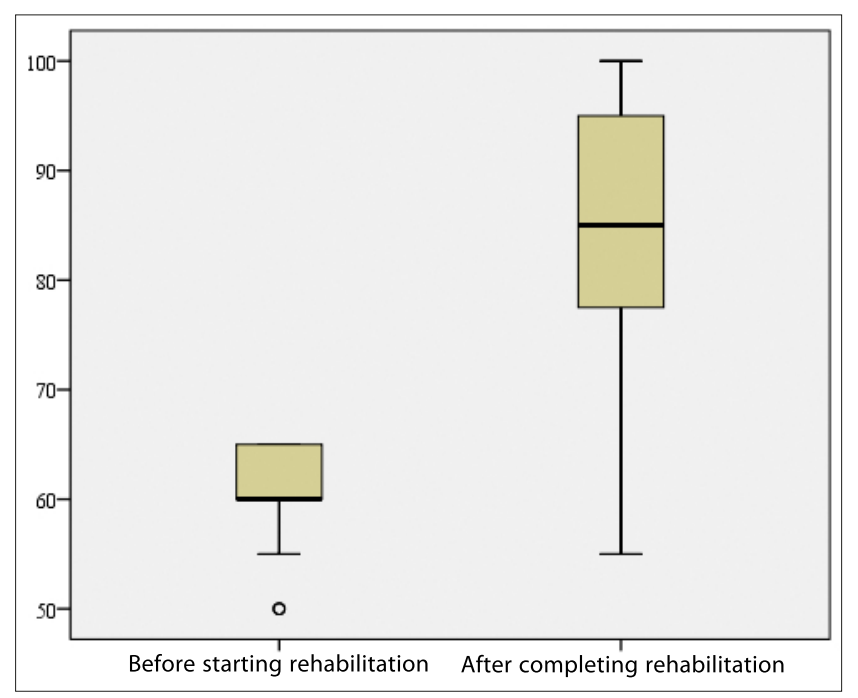

Figure 1. The efficiency and independence of DCC patients examined with use of Barthel index

Table 1. Efficiency and independence of DCC patients examined with use of Barthel index

\begin{tabular}{|c|c|c|c|c|c|c|c|c|}
\hline \multicolumn{6}{|c|}{ Test } & \multirow{2}{*}{\multicolumn{3}{|c|}{ Intra-group comparison }} \\
\hline \multicolumn{3}{|c|}{$\begin{array}{l}\text { Before starting } \\
\text { rehabilitation }\end{array}$} & \multicolumn{3}{|c|}{$\begin{array}{l}\text { After completing } \\
\text { rehabilitation }\end{array}$} & & & \\
\hline $\mathrm{Me}$ & Q1 & Q3 & Me & Q1 & Q3 & $z$ & $\mathrm{p}$ & $\mathrm{rc}$ \\
\hline 60.00 & 60.00 & 65.00 & 85.00 & 76.00 & 95.00 & 5.41 & 0.001 & 0.69 \\
\hline
\end{tabular}

Me-median; Q1-quartile 1; Q3 - quartile 3; Z-value of the Wilcoxon test statistic; $\mathrm{p}$ - significance level; rc - value of r Cohen matched pair, biserial rank correlation coefficient.

The conducted analyzes demonstrated that prior to the rehabilitation, the DCC patients - to some extent - required the care of other people $\left(M e=60.00 ; Q_{1}=60.00 ; Q_{3}=65.00\right)$, but after completion of the rehabilitation programme they could function independently using only a small amount of help $\left(M e=85.00 ; Q_{1}=76.00 ; Q_{3}=95.00\right)$.

The performed intergroup comparisons show that the efficiency and independence of DCC patients was statistically significantly higher after the end of the rehabilitation cycle than before its commencement $(Z=5.41 ; p=0.001)$.

The obtained effect size $\left(r_{c}=0.69\right)$ confirms a strong relationship between the applied kinesiotherapy programme and the level of fitness and independence of the subjects.

Results of the performed intergroup comparisons in the range of results obtained in the I-ADL scale are included in Table 2 and Figure 2.

Based on the data obtained, it was found that before starting the rehabilitation programme, the DCC patients were seriously dependent on the help of other people during the instrumental activities of everyday life $(M e=18.00 .00$; $\left.Q_{1}=16.00 ; Q_{3}=21.00\right)$, while after its completion they needed 


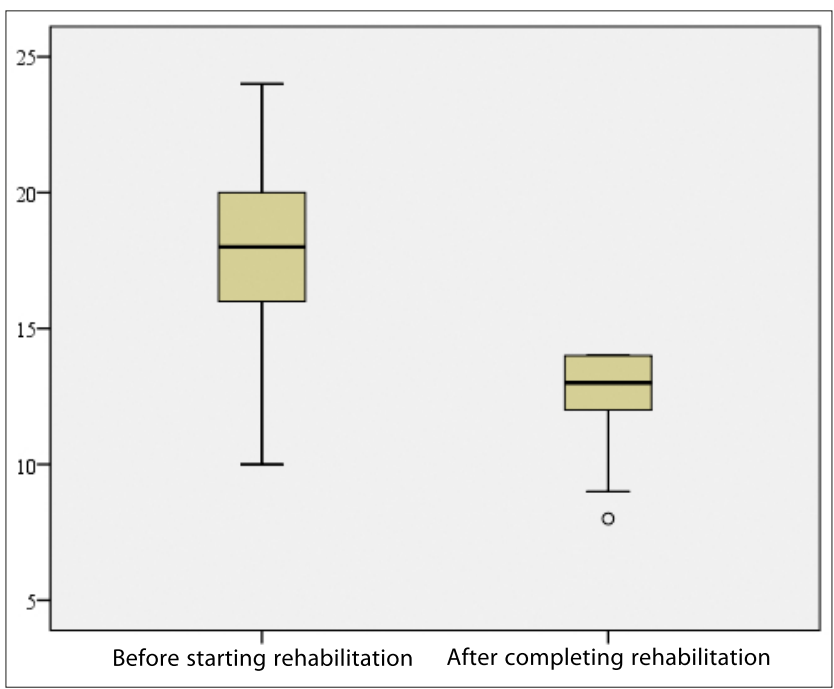

Figure 2. Instrumental activities of daily living of DCC patients examined using the I-ADL scale

Table 2. Instrumental activities of daily living of DCC patients examined using the I-ADL scale

\begin{tabular}{|c|c|c|c|c|c|c|c|c|}
\hline \multicolumn{6}{|c|}{ Test } & \multirow{2}{*}{\multicolumn{3}{|c|}{ Intra-group comparison }} \\
\hline \multicolumn{3}{|c|}{$\begin{array}{l}\text { Before starting } \\
\text { rehabilitation }\end{array}$} & \multicolumn{3}{|c|}{$\begin{array}{l}\text { After completing } \\
\text { rehabilitation }\end{array}$} & & & \\
\hline $\mathrm{Me}$ & Q1 & Q3 & $\mathrm{Me}$ & Q1 & Q3 & Z & $\mathrm{P}$ & $\mathrm{rc}$ \\
\hline 18.00 & 16.00 & 21.00 & 13.00 & 12.00 & 14.00 & 2.63 & 0.009 & 0.34 \\
\hline
\end{tabular}

Me-median; $Q_{\text {- }}$-quartile $1 ; Q_{3}$-quartile $3 ; Z$-value of the Wilcoxon test statistic; $p$-significance level; $r$ - value of a $r$ Cohen matched pair, biserial rank correlation coefficient.

help from others only to a moderate extent $\left(M e=13.00 ; Q_{1}=12\right.$; $Q_{3}=14.00$ ).

The performed intergroup comparisons demonstrated that the efficiency of performing everyday instrumental activities in DCC patients was statistically significantly higher after the end of the rehabilitation cycle than before its commencement $(Z=2.63 ; p=0.009)$.

The obtained effect size $(r=0.34)$ confirms the average relationship between the rehabilitation programme used and the subjects' level of fitness in the instrumental activities of everyday.

Results of the performed intergroup comparisons in the range of results obtained in the VES-13 scale are included in Table 3 and Figure 3.

The calculations indicate that prior to the rehabilitation programme, the DCC patients were characterized by increased susceptibility to the occurrence of geriatric health problems $\left(M e=9.00 .00 ; Q_{1}=7.00 ; Q_{3}=11.00\right)$, whereas after its completion the risk assessed against the potential range of the variable was moderate $\left(M e=5.00 ; Q_{1}=4.00 ; Q_{3}=5.00\right)$.

Intergroup comparisons show that the risk of health problems in DCC patients was statistically significantly lower after the rehabilitation cycle was completed than before its commencement $(Z=5.47 ; p=0.001)$.

The obtained effect size $(r=0.71)$ confirms the strong dependence between the rehabilitation programme applied and the subject's vulnerability to the occurrence of geriatric health problems.

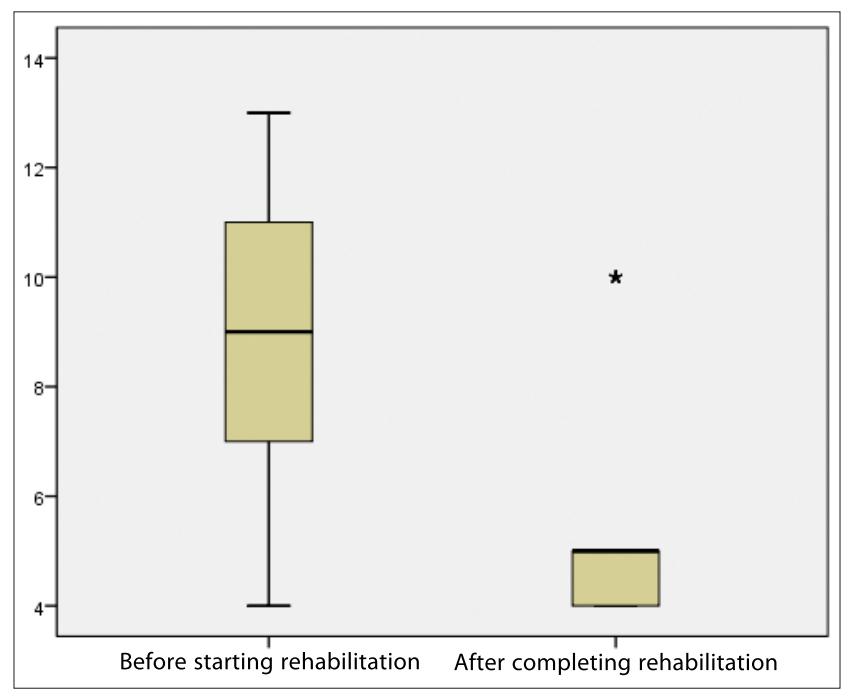

Figure 3. The risk of geriatric health problems in DCC patients examined using the VES-13 scale

Table 3. Risk of geriatric health problems in DCC patients examined using the VES-13 scale

\begin{tabular}{|c|c|c|c|c|c|c|c|c|}
\hline \multicolumn{6}{|c|}{ Test } & \multirow{2}{*}{\multicolumn{3}{|c|}{ Intra-group comparison }} \\
\hline \multicolumn{3}{|c|}{$\begin{array}{l}\text { Before starting } \\
\text { rehabilitation }\end{array}$} & \multicolumn{3}{|c|}{$\begin{array}{l}\text { After completing } \\
\text { rehabilitation }\end{array}$} & & & \\
\hline $\mathrm{Me}$ & Q1 & Q3 & $\mathrm{Me}$ & Q1 & Q3 & Z & $P$ & $\mathrm{rc}$ \\
\hline 9.00 & 7.00 & 11.00 & 5.00 & 4.00 & 5.00 & 5.47 & 0.001 & 0.71 \\
\hline
\end{tabular}

Me-median; Q1-quartile 1; Q3 - quartile 3; Z-value of the Wilcoxon test statistic; p-significance level; rc - value of a r Cohenmatched pair, biserial rankcorrelation coefficient.

\section{DISCUSSION}

The analyzes carried out demonstrated that as a result of the kinesiotherapy programme, the overall functional fitness and independence in performing everyday instrumental activities increased, while the risk of geriatric health problems in the examined population of people using medical care in DCC was minimized, which undoubtedly contributed to lowering the needs for the care of the group in question.

Significant improvement in health parameters and functional capacity of seniors was also demonstrated by research conducted in Korea. As a result of a 12-week intervention in a social care centre, which was aimed at promoting physical activity and other health behaviours in people over 65 years of age, the desired effects in terms of blood pressure, heart rate, balance and other factors responsible for the functional efficiency of seniors were obtained [19].

The meta-analysis conducted by Bouaziz shows that the observed effects may be the result of improved cardiorespiratory fitness, which is conducive not only to achieving and maintaining functional capacity, but also to maintaining good health. It has been demonstrated that regular physical activity, and in particular aerobic training, minimizes the risk of geriatric health problems in the elderly. This effect was observed both in a group of healthy people and those with chronic diseases [20].

Analogical regularities were also confirmed in the case of a much older group of seniors with diagnosed mood disorders. 121 people, whose average age was 75 years, participated in the research. Participants performed physical exercises 
adapted to their physical state for a period of 3 weeks. On the basis of the performed analyzes, it was found that the applied rehabilitation intervention contributed to the improvement of cognitive functioning (visual and spatial functions) and increased independence of the subjects [21].

Hagovská and Olekszeová also found a significant improvement in the ability to live independently of the elderly after an applied kinesiotherapy programme. The study included a population of seniors with a diagnosis of mild cognitive impairment. Patients from the experimental group performed a 30-minute physical training combined with exercises to improve the balance for 10 weeks, while people belonging to the control group performed only balance-improving exercises throughout this period. It turned out that the combination of aerobic training and balance exercises contributed to achieving better results in terms of functional efficiency of patients than the balance training itself [22].

The study results are associated with some limitations, among which the specificity of the studied group should be mentioned. It consisted of $60 \mathrm{DDOM}$ patients who participated in the cycle of comprehensive outpatient rehabilitation. Although all participants completed the study, it should be pointed out that in relation to the entire population of seniors from Lublin, this is a small percentage of people. Therefore, the possibility of generalization of the research results to a wider population seems to be limited. In addition, the research measured the autonomy of the subjects in the scope of performing basic and advanced everyday activities, and the level of risk of occurrence of geriatric health problems using questionnaire methods, based on which it is possible to formulate conclusions about observed regularities with a certain level of probability.

However, it should be noted that despite the existing limitations, the obtained data are of cognitive and practical significance, because they deepen knowledge in the field of medical sciences and confirm that the applied intervention in the form of daily outpatient care, comprehensive geriatric assessment and rehabilitation, including adapted endurance training, proved to be highly effective in preventing sociohealth problems resulting from the aging processes.

It seems that geriatric rehabilitation should include elements of physical activation in the form of endurance training, which improves the function of skeletal muscles and cardiovascular and respiratory systems, and also positively affects the activities of the central nervous system $[23,24]$.

\section{CONCLUSIONS}

1. The applied programme of comprehensive outpatient rehabilitation aimed at people aged over 60 increased the independence of the participants in the field of basic and advanced activities of everyday life.

2. The applied programme of comprehensive ambulatory rehabilitation resulted in lowering the risk of age-related health problems assessed using the VES-13scale.

\section{REFERENCES}

1. Ginnakouris K. Aging characterizes the demographic perspectives of the European societies. Eurostat. Statistics in Focus. 2008; 72: 1-11.

2. Łukasik A, Barylski M, Irzmański R. Rehabilitacja osób w wieku podeszłym - terapia z wyboru dla starzejącego się społeczeństwa. Geriatria. 2011; 5: 315-323.

3. Żak M. Determinanty powtarzalności upadków u osób po 75 roku życia. Kraków Akademia Wychowania Fizycznego, 2009.

4. Wei N, Pang MY, Ng SS, Ng GY. Optimal frequency/time combination of whole body vibration training for developing physical performance of people with sarcopenia: a randomized controlled trial. Clin Rehabil. 2017; 31 (10): 1313-1321.

5. Institute of Rural Medicine. Dailycare Centre in Lublin. http://www. imw.lublin.pl/index.php/pl/rejestracja-ddom (accessed: 2018.07.03.).

6. Leardini G, Salaffi F, Caporali R, Canesi B, Rovati L, Montanelli R. Direct and indirect costs of osteoarthiritis of the knee. Clin Exp Rheumatol. 2004; 22 (6): 699-706.

7. March LM, Bachmeier CJ. Economics of osteoarthiritis: a global perspective. BaillieresClinRheumatol. 1997; 11 (4): 817-834.

8. Osiński W. Gerokonezjologia. Nauka i praktyka aktywności fizycznej w wieku starczym. Warszwa Wydawnictwo PZWL, 2013.

9. Aminzadeh F, Dalziel WB. Older adults in the emergency department: a systematic revival of patterns of use, adverse outcomes and effectiveness of interventions. Ann. Emerg. Med. 2002; 39: 238-247.

10. Xu XF, Chen Q, Zhao YP, Hu XY. Investigation and analysis of the activities of daily living of the aged at home in western China. Beijing Da Xue Xue Bao Yi Xue Ban. 2018; 18, 50 (3): 457-462.

11. Saliba S, Elliot M, Rubenstein LA, Salomon DH, Young RT, Kamberg CJ, Roth C, MacLean CH, Shekelle PG, Sloss EM, Wenger NS. The Vulnerable Elders Survey (VES-13): A Tool for Identifying Vulnerable Elders in the Community. J Am Ger Soc. 2001; 49: 1691-1699.

12. Min L, Yoon W, Mariano J, Wenger N, Elliot M, Kamberg C, Saliba D. The vulnerable elders-13 survey predicts 5 -year functional decline and mortality outcomes in older ambulatory care patients. J Am Geriatr Soc. 2009; 57: 2070-2076.

13. Min L, Elliot M, Wenger N, SAliba D. Higher vulnerable elders survey scores predict death and functional decline in vulnerable older people. J Am Geriatr Soc. 2006; 54: 507-511.

14. GUS (Central Statistical Office of Poland). Rocznik statystyczny RP 2017. Warsaw: Zakład Wydawnictw Statystycznych, 2017.

15. Bień B. Sytuacja zdrowotna osób w podeszłym wieku. In: Grodzicki T, Kocemba J, Skalska A, editors. Geriatria z elementami gerontologii ogólnej. Via Medica, Gdańsk; 2007. pp. 42-46.

16. Yang JE, Lee TY, Kim JK.The effect of a VR exercise program on falls and depression in the elderly with mild depression in the local community. J Phys Ther Sci. 2017; 29 (12): 2157-2159.

17. Mahoney FI, Barthel, D. Functional Evaluation: The Barthel Index. Md State Med J. 1965; 14: 61-65.

18. Lawton MP, Brody EM, Assessment of older people: self-maintaining and instrumental activities of daily living. Gerontologist. 1969; 9(3): 179-86.

19. Lee HY, Kim J, Kim KS. The Effects of Nursing Interventions Utilizing Serious Games That Promote Health Activities on the Health Behaviors of Seniors. Games Health J. 2015; 4(3): 175-182.

20. Bouaziz W, Kanagaratnam L, Vogel T, Schmitt E, Dramé M, Kaltenbach G, Geny B, Lang PO. Effect of Aerobic Training on Peak Oxygen Uptake Among Seniors Aged 70 or Older: A Meta-Analysis of Randomized Controlled Trials. Rejuvenation Res. 2018. doi: 10.1089/rej.2017.1988.

21. Neviani F, Belvederi Murri M, Mussi C, Triolo F, Toni G, Simoncini E, Tripi F, Menchetti M, Ferrari S, Ceresini G, Cremonini A, Bertolotti M, Neri G, Squatrito S, Amore M, Zanetidou S, Neri M. Physical exercise for late life depression: effects on cognition and disability. Int Psychogeriatr. 2017; 29(7): 1105-1112.

22. Hagovská M, Olekszyová Z, Impact of the combination of cognitive and balance training on gait, fear and risk of falling and quality of life in seniors with mild cognitive impairment. Geriatr Gerontol Int. 2016; 16(9): 1043-1050. doi: 10.1111/ggi.12593.

23. van Gelder BM, Tijhuis MR, Kalmijn S, Giampaoli S, Nissinen A, Kromhout D. Physical activity in relation to cognitive decline in elderly men: the FINE Study. Neurology. 2004; 63(12): 2316-2321.

24. Mazurek K, Żmijewski P, Kozdroń E, Fojt A, Czajkowska A, Szczypiorski P, Mazurek T. Cardiovascular risk reduction in sedentary postmenopausal women during organized physical activity. Kardiol Pol. 2017; 75(5): 476-485. 